\title{
LOS "MENSAJES PARA EL CAMPO", ELEMENTO COMUNICATIVO IDENTITARIO DE LA COMUNIDAD DE HABLA MAGALLÁNICA. ${ }^{1}$
}

\author{
MARGARITA MAKUC
}

\section{RESUMEN}

El servicio de mensajería radial "Mensajes para el campo", constituye uno de los elementos más arraigados en la identidad social y cultural en la región de Magallanes. Se origina en los inicios de la radio en los años veinte y se estableció como un canal de comunicación entre las áreas urbanas y rurales de la región. Este tipo de mensajes, muestra elementos propios del mundo rural patagónico, así como de la cultura que rodea el mundo estanciero (Martinic y Buratovic, 2007).

El presente artículo analiza los elementos lingüísticos que remiten al contexto de situación; dado que éste se expresa mediante elementos textuales que definen un determinado tipo de discurso (Halliday, 1975, Beaugrande y Dressler, 1997; Renkema, 1999; Alvarez, 2004).

Entre las conclusiones principales, en los textos analizados se observa la presencia de dé́cticos "de ocultamiento de información" que remiten a personas, lugares y situaciones ausentes, propios de una situación discursiva que exige al productor de estos discursos desarrollar una serie de estrategias discursivas caracterizadoras de este tipo de mensajes. Finalmente, se destaca que "Los Mensajes para el campo" tienen características textuales propias y definidas, que reflejan no sólo particularidades de la región, en cuanto a la función social que ellos cumplen, sino además porque forman parte de la historia de las comunicaciones, espacios radiales que aún persisten y que distinguen a la comunidad de habla magallánica y de la radiofonía de las regiones apartadas en la Patagonia.

PALABRAS CLAVES: Contexto de situación, campo, tenor, modo, registro.

1 Artículo elaborado en el marco del Proyecto Interno de Investigación: "Estudio sociolingüístico de la comunidad de habla magallánica en el nivel discursivo de la lengua a partir de variaciones morfológicas, sintácticas y semánticas registradas en la interacción comunicativa en los hablantes de la XII región" (PR-F4-EH-09) Dirección de investigación, Universidad de Magallanes.

Universidad de Magallanes, Facultad de Humanidades, Ciencias Sociales y de la Salud, Av. Bulnes 01855, Punta Arenas, Chile, e-mail: margarita.makuc@umag.cl 


\section{THE "MENSAJES PARA EL CAMPO" ("MESSAGES FOR THE COUNTRYSIDE”), IDENTIFYING COMMUNICATIVE ELEMENT OF THE MAGALLANIC SPEAKING COMMUNITY.}

\section{ABSTRACT}

The radio message service "Mensajes para el campo" (Messages for the countryside), is one of the most rooted elements in the social and cultural identity in the region of Magallanes. It originates at the beginning of the radio in the twenties and was established as a channel of communication between the urban and rural areas of the region. This type of message shows elements typical of the Patagonian countryside, as well as of the culture which surrounds the rancher world (Martinic y Buratovic, 2007).

This article analyzes the linguistic elements which refer to the context of situation; since it is expressed through textual elements that define a particular type of discourse (Halliday, 1975, Beaugrande y Dressler, 1997; Renkema, 1999; Alvarez, 2004).

Among the main findings, in the analyzed texts we observe the presence of deictic "of concealment of information" which refer to absent people, places and situations, characteristic of a discursive situation that requires the producer of these discourses to develop a series of discursive strategies characterizing of this type of messages. Finally, we emphasize that the "Messages for the countryside" have their own textual and defined characteristics, which reflect not only the characteristics of the region, in terms of social function they fulfill, but also because they are part of the history of communications, radio programs that still remain and that distinguish the Magellan speaking community and the radio from remote regions in Patagonia Patagonia.

KEYWORDS: Context of de situation, countryside, tenor, mode, register.

\section{INTRODUCCIÓN}

El estudio de los textos definidos como "Mensajes para el campo", nos plantea la posibilidad de integrar en el análisis tanto la dimensión lingüística como comunicativa. Desde la lingüística textual, la noción de texto se considera un concepto polisémico, sin embargo reúne ciertas características en torno a las cuales existe consenso entre diversos autores (Kintsch y van Dijk, 1978; van Dijk, 1998). Por una parte, respecto del texto se plantea que éste presentaría, una estructura construccional constituida por elementos lingüísticos organizados según determinadas reglas de construcción; así como desde un punto de vista semántico-funcional, constituiría una unidad semántica que tiene función ideacional, interpersonal y textual (Halliday, 1994a; Alvarez, 2004).

Por otra parte, se ha planteado que la noción de texto es indisociable de la noción de discurso, pues nos remite a la capacidad de hacer funcionar los textos en situaciones de comunicación determinadas, ante un destinatario determinado, para obtener objetivos extra-lingüísticos determinados.
Desde esta perspectiva, el texto conservaría las huellas de la situación del discurso remitiéndonos, tanto a sus condiciones de producción como de recepción. Al respecto Ducrot (1980) señala: el sujeto productor del discurso inscribe en su texto las marcas de su situación, como también las marcas de su destinatario real o imaginario. Estas marcas se expresarían en dos niveles: nivel discursivo, es decir, en el marco de una situación de comunicación específica, o contexto de situación (Eggins y Martin, 2003) y en el nivel construccional esto es, en elementos observables desde el punto de vista lingüístico-configuracional.

En este contexto, en nuestro estudio integraremos en el análisis el nivel construccional y discursivo, considerando que los Mensajes para el Campo forman parte de una "comunidad de habla" específica. Desde un enfoque sociolingüístico, la comunidad de habla se caracterizaría por constituir un grupo delimitado geográficamente que se distingue de otros grupos similares por diferencias significativas en el uso de la lengua y que además comparte normas, actitudes, y valoraciones de su propia lengua (Labov, 1983; Silva, 1989). Desde este mismo enfoque, la 
variación se puede expresar en una comunidad de habla concreta en los distintos niveles de la lengua: fonético, morfológico, sintáctico, semántico, léxico y textual. En este sentido, proponemos abordar "Los mensajes para el campo" como un tipo de texto que reúne características particulares que plasman aspectos de la identidad regional, reflejando en su análisis aspectos geográficos, culturales, sociales e históricos propios de la comunidad de habla magallánica.

En el caso de la región de Magallanes, la comunidad de habla en que se presentan los mensajes para el campo presenta ciertas características específicas que la distinguen del resto de las regiones del país: la situación de aislamiento dada su ubicación geográfica (Martinic, 1972, 2006), las vertientes que han intervenido en el poblamiento, la organización social determinada por la actividad ganadera ovina, petrolera y comercial, todo lo cual nos obliga a referirnos en forma particular a la construcción de la identidad de la región. La identidad Fuego-Patagonia se puede entender como un proceso de múltiples orígenes, las corrientes migratorias contribuyen de manera integrada y sintetizada a la construcción del ser regional. Desde este punto de vista, los aportes que entregaron a estos territorios los inmigrantes chilotes, españoles, croatas, suizos, alemanes, británicos, hindúes, entre otros, se amalgamaron en función de los espacios y escenarios específicos en los cuales se localizaron. Cabe señalar, que en Magallanes y Tierra del Fuego, a diferencia de lo que acontece en otras zonas del país, representa la confluencia de diversos flujos culturales y nacionales; lo que ha originado la formación de una sociedad multicultural que reconoce estar conformando una comunidad de habla singular (Martinic, 2006)

Dentro de las características propias de la región, algunas zonas particulares de Fuego-Patagonia aparecen con rasgos distintivos propios, esto se traduce en una separación entre lo rural y lo urbano, y entre la pampa y el litoral. La actividad ganadera constituye la actividad central de las comunidades rurales, de este modo oficios como el del peón, el ovejero o el esquilador, han mantenido conocimientos y actividades culturales de la pampa, lo que se evidencia en el lenguaje, el vestuario gaucho y otras peculiaridades. La pampa patagónica, como se denomina comúnmente al sector de la estepa, está históricamente relacionada con actividades ganaderas. Un rasgo interesante de Magallanes es su pertenecía patagónico-oriental, este hecho ha motivado que su población sea partícipe de la gran comunidad atlántica americana asemejándose y compartiendo rasgos comunes con comunidades regionales de la Patagonia. (Martinic, 2006). En síntesis "Los mensajes para el campo" forman parte de una comunidad de habla cuyos discursos plasman una identidad regional patagónica, caracterizada por la situación de aislamiento, la actividad ganadera ovina y la cercanía con la Patagonia argentina.

En este contexto de aislamiento, como hecho geográfico y como fenómeno social (Martinic, 2006) la radiofonía se constituye en un elemento de integración en la Patagonia austral. Los orígenes de este medio de comunicación se remontan al año 1927 y rápidamente provoca un significativo cambio en la sociedad al romper el aislamiento territorial, social, familiar e individual en que virtualmente se estaba hasta fines de los años veinte. Indudablemente, la radiodifusión fue el sistema de comunicación a distancia que tuvo la mayor trascendencia social en el período extendido entre 1920 y 1970 (Martinic y Buratovic, 2007). De este modo, la influencia social de la radioemisión comercial fue relevante, sus servicios llegaron a tener la condición de indispensables para la vida de la comunidad; como medio de comunicación pudo ofrecer una gama de posibilidades y servicios referidos tanto a la transmisión de información general como aquellos orientados al entretenimiento y la cultura. En este contexto de desarrollo, surgen en la Radio "Austral" (CD 111) los "Mensajes para el Campo", espacios radiales que fueron especialmente creativos y con una utilidad práctica en la vida de los habitantes de Magallanes. Estos mensajes se emitían diariamente (al medio día) en un horario fijo y estaban dirigidos preferentemente a los habitantes de las zonas rurales. Este servicio radial, surgido en la ciudad de Punta Arenas, tuvo tal efectividad que fue replicada tanto por emisoras nacionales (Chiloé, Llanquihue y Aysén) como argentinas, su utilidad pública ha quedado en evidencia, pues aún cuando existen en la actualidad diversos y modernos modos de comunicación, los "Mensajes para el Campo" persisten como servicio comunitario y han demostrado durante todos estos años en que han formado parte de la identidad regional, un caso histórico de aporte magallánico en las comunicaciones a distancia. 
Desde un punto de vista lingüístico, los mensajes para el campo constituyen un tipo de texto que refleja las huellas de la situación comunicativa, constituyendo una expresión de la variación dialectal de la comunidad de habla en estudio. El presente estudio, se realiza desde la perspectiva SistémicoFuncional (Halliday, 1994 a y b), por cuanto aborda el análisis lingüístico de los textos considerando la situación social como parte fundamental en el proceso construccional de un texto. El enfoque funcional sugiere considerar la cláusula como la unidad léxicogramatical que concentra el significado del lenguaje, desde ella es posible acceder al significado del texto, en sus funciones ideacional, interpersonal y textual. Desde esta perspectiva, el texto se considera una unidad semántica definida por el componente textual, que posee una estructura genérica, es producto de su entorno y funciona en él. En otras palabras, el texto se interpreta como un proceso que expresa las órdenes superiores del significado que constituyen la semiótica social, es decir los sistemas de significado de la propia cultura que los produce. (Halliday y Hasan, 1976; Halliday,1989, 1994)

El enfoque Sistémico-Funcional propone el concepto de registro para explicar la adecuación del texto al contexto, esto es, la variedad de lengua determinada por la situación comunicativa, desde esta perspectiva la variación se considera potencialmente significativa, por lo tanto, cualquier conjunto de alternativas puede llegar a ser portador de informaciones y valores sociales; en este sentido, la variación según el registro expresaría la diversidad de los procesos sociales (Halliday, 1989). De este modo, observamos que registro es un concepto sociolingüístico definido por las variables que concurren situacionalmente $y$, al mismo tiempo es un concepto materializado en unas determinadas características lingüísticas. En otros términos, el registro es una variedad de lengua caracterizada por su gramática y su léxico, de acuerdo con la función retórica y la adaptación a una situación comunicativa concreta. En otras palabras, todo tipo de texto o discurso tiene una estructura genérica, la que puede explicarse dentro del marco del concepto de "registro", los significados constituyen un registro, más que las propias estructuras lingüísticas, de modo que el registro de un texto puede ser considerado un macro nivel con una dinámica retórica y realización gramatical específica; en síntesis, el registro puede ser definido como un marco retórico-gramatical donde se actualiza la lengua y se realizan las manifestaciones del discurso y las variedades lingüísticas.

Desde el enfoque sistémico funcional las propiedades semióticas de un particular tipo de situación determinan el registro: el potencial de significado que es característico del tipo de situación y que es realizado en lo que se conoce como "variante de habla", circunscriben la forma lingüística del texto en la interacción social. El desarrollo del concepto de registro ofrece una clasificación que describe los componentes situacionales que organizan lingüísticamente el registro, éstos se definen como campo tenor modo y distinguen muy claramente las diferentes situaciones de la conducta lingüística, se trata, de acuerdo con Eggins y Martin (2003) de una realización de dos perspectivas: la manera en que el campo, tenor y modo condicionan el significado ideacional, interpersonal y textual respectivamente y la manera en que las diferentes selecciones lingüísticas de estos componentes construyen los diferentes tipos de campo tenor y modo. Esta sistemática unión entre la organización de la lengua y la organización del contexto, se desarrolla en la tres dimensiones analíticas: campo, tenor y modo que forman parte de la noción de registro; en términos generales, el concepto de campo describe el tema o la actividad descrita en un texto; la noción de tenor permite caracterizar la relación entre emisor y receptor, aportando información acerca de la relación interpersonal entre emisor y comunidad discursiva, y, finalmente, el modo, abre la posibilidad de un análisis léxico semántico y gramatical del registro.

\section{COMPONENTES DEL REGISTRO TEXTUAL: CAMPO, TENOR Y MODO}

Como se ha señalado, los elementos del nivel construccional del texto: campo, tenor y modo, constituyen una estructura conceptual que permite representar el contexto social como entorno semiótico en que la gente intercambia significados, a continuación estas nociones se describen en detalle:

a) Campo: Corresponde a la acción social en que el texto está encapsulado, pertenece al factor de la situación que se refiere a la esfera de la actividad y temática tratada, es decir lo que están haciendo los participantes en lo que el lenguaje figura como un 
componente esencial (Halliday, 1994aㅡ y b; Eggins y Martin, 2003). En este sentido el léxico sería un indicador revelador de la temática y por tanto del campo (Calsamiglia, y Tusón, 2007)

b) Tenor: Se refiere al conjunto de relaciones de papeles entre los participantes importantes. Comprende la estructura de roles: quién participa, la naturaleza de los participantes, qué tipo de relaciones se da entre los participantes, tanto los tipos de roles de habla en el diálogo como el variado conjunto de relaciones sociales en que participan (Eggins y Martin, 2003).

c) Modo: Este factor situacional se refiere a las diversas formas de canalización o transmisión del mensaje, ya sea oral, escrito y sus múltiples maneras de combinarse. Es decir, corresponde a la organización simbólica del texto, a la explicitación de la función del lenguaje en una situación comunicativa concreta. En otras palabras, este componente permite a los participantes utilizar los recursos lingüísticos en una situación determinada integrando la función del texto en el contexto. De esta manera, el Modo incluye, no sólo el canal oral o escrito (y/o la combinación de ambos); sino además, la modalidad retórica del texto en términos de categorías como persuasiva, expositiva, didáctica (Eggins y Martin, 2003).

\section{METODOLOGÍA Y PROCEDIMIENTOS}

Los procedimientos de investigación utilizados en el marco de este estudio corresponden a las metodologías tradicionales de la investigación sociolingüística (Almeida, 2003, Álvarez, 2004, Calsamiglia y Tusón, 2007).

En una primera fase se procedió a recopilar "Mensajes para el campo" recibidos y emitidos por la radio "Polar" (CD 89) de Punta Arenas (Frecuencia 960 AM) en el período de julio de 2007, 2008 y julio de 2009; para estos efectos e se revisaron los archivos de la radioemisora lo cual permitió extraer una muestra de 150 mensajes que presentaran características de legibilidad y diversidad de localidades y comunas rurales a las cuales estaban dirigidos. De este modo, estos mensajes seleccionados constituyeron el Corpus de estudio de esta investigación.

$\mathrm{El}$ análisis de los mensajes se realizó identificando y caracterizando en el nivel discursivo los elementos que conforman el campo, tenor y modo en los textos "Mensajes para el campo".

\section{OBJETIVOS DEL ESTUDIO}

1.- Identificar los elementos lingüísticos que remiten al contexto de situación y que definen un determinado tipo de texto.

2- Caracterizar las tres dimensiones del registro textual: campo, tenor y modo en los "Mensajes para el campo".

3.- Determinar las características lingüísticodiscursivas que constituyen una variedad textual dialectal que refleja elementos propios de la cultura magallánica.

\section{PRESENTACIÓN Y DISCUSIÓN DE RESULTADOS}

La presentación de resultados se organiza en torno a las tres dimensiones del registro textual: campo, tenor y modo. Estas dimensiones se abordan a partir del léxico, el rol de los participantes y la modalidad retórica predominante en los textos seleccionados. A continuación se describen los elementos lingüísticos que se observaron en el análisis de cada una de las dimensiones de los textos:

1.- Campo: el análisis del tema y la actividad social se aborda a partir de los elementos léxicos recurrentes en este tipo de mensajes, podemos señalar que éstos se sitúan en el contexto rural (ámbito ganadero) y sus principales temáticas son laborales, estos mensajes transmiten contenidos vinculados con la actividad agropecuaria mediante la comunicación radiofónica. Al mismo tiempo, se comunican situaciones vinculadas con la vida cotidiana de los habitantes de la ciudad hacia la estancia o viceversa, en ellos podemos observar el predominio de temáticas familiares y de la vida privada.

En las tablas 1 a 3 se presenta una selección de mensajes que permiten observa el predominio de léxico que representa al mundo rural en su dimensión laboral y familiar.

2.- Tenor: las características de la estructura de roles de los participantes se inscribe en el tipo de interacción que establecen los participantes de estos mensajes (emisor-destinatario), en la interacción laboral las relaciones apreciadas corresponden en su mayoría a relaciones laborales entre administrador de estancia, capataz, trabajador. Mientras que en la temática familiar se aprecian relaciones familiares de tipo afectivo, esposa/marido; hijo/padre; novia/novio. 
Tabla 1. Selección de elementos léxicos que evidencian las temáticas predominantes (Campo).

\begin{tabular}{|l|l|}
\hline \multicolumn{1}{|c|}{ Temática laboral } & \multicolumn{1}{c|}{ Temática familiar } \\
\hline Encierra unos 8 borregos machos del 2 para mañana al medio día. & $\begin{array}{l}\text { Papá trata de bajar. no pude solucionar nada con mi abuelo. } \\
\text { ya que este no puede hacer lo acordado. y requiero lo que te } \\
\text { pedí. besos te quiero mucho. }\end{array}$ \\
\hline Ruego tener tranquera abierta temprano ya que va camión. & $\begin{array}{l}\text { A Vicente su prometida necesita que baje urgente a Punta } \\
\text { Arenas, muchos besos te espero. }\end{array}$ \\
\hline Ruego que me lleven 100 o 200 borregos a la estancia. & $\begin{array}{l}\text { Se ruega bajar a Porvenir...porque llego una carta de Corona } \\
\text { por una deuda que tienes que pagar antes del } 30 \text { de este mes } \\
\text { yo te explico lo demás. }\end{array}$ \\
\hline No rodee animales hasta el día martes. & $\begin{array}{l}\text { Bajar para solucionar un problema urgente de su casa (no } \\
\text { te pagaron). }\end{array}$ \\
\hline Faene un consumo, yo pasaré a buscarlo. & $\begin{array}{l}\text { Desde la distancia te saludo con mucho cariño por ser hoy } \\
\text { 28 de noviembre. }\end{array}$ \\
\hline Día sábado a 1ra hora va camión a retirar ovejas. & $\begin{array}{l}\text { Para José en Puerto Porvenir o donde se encuentre vaya } \\
\text { a esa el sábado espero que puedas viajar, tengo que hablar } \\
\text { urgente contigo. }\end{array}$ \\
\hline Rodea mañana campo de corderos. & \begin{tabular}{l} 
Bajar para solucionar un problema urgente de su casa. \\
\hline
\end{tabular}
\end{tabular}

Tabla 2. Tipo de relación de acuerdo a la estructura de roles de los participantes (Tenor).

\begin{tabular}{|c|c|}
\hline RELACIONES LABORALES & RELACIONES FAMILIARES \\
\hline Deje en el puesto llave del puente Miraflores. & $\begin{array}{l}\text { Para papá llegamos mañana a alguna hora. estamos todos } \\
\text { bien. muchos besos. }\end{array}$ \\
\hline Lo que tú sabes probablemente hasta fines de septiembre. & $\begin{array}{l}\text { La mama sigue enferma. te ruego pongas en contacto lo } \\
\text { antes posible. }\end{array}$ \\
\hline $\begin{array}{l}\text { Favor encierra unos } 8 \text { borregos machos del } 2 \text { para mañana } \\
\text { al medio día. }\end{array}$ & $\begin{array}{l}\text { Tío, comunico que Andrea continúa delicada de salud. está } \\
\text { hospitalizada. }\end{array}$ \\
\hline $\begin{array}{l}\text { Mensaje sector laguna blanca se comunica que mañana sábado } \\
\text { pasara piño de vacunos por verenada. }\end{array}$ & $\begin{array}{l}\text { Su prometida necesita que baje urgente a Punta Arenas, } \\
\text { muchos besos te espero. }\end{array}$ \\
\hline $\begin{array}{l}\text { Para don Félix mañana viernes a medio día estoy en la estancia } \\
\text { para revisar el lote de ovejas secas. atte. }\end{array}$ & $\begin{array}{l}\text { Ruego solucionar problema bancario en Puerto Natales. espero } \\
\text { baje a esa antes del jueves. }\end{array}$ \\
\hline
\end{tabular}

Tabla 3. Distribución de Mensajes para el campo de acuerdo a temática (Campo) y relación entre los participantes (Tenor).

\begin{tabular}{|c|c|c|c|}
\hline $\begin{array}{c}\text { Mensajes con temática } \\
\text { y relación laboral }\end{array}$ & $\begin{array}{c}\text { Mensajes con temática } \\
\text { y relación familiar }\end{array}$ & Otros & Total \\
\hline$(87)$ & $(57)$ & $(6)$ & $(150)$ \\
$58 \%$ & $38 \%$ & $4 \%$ & $100 \%$ \\
\hline
\end{tabular}

3.-Modo: Esta dimensión del análisis se manifiesta en dos características de los mensajes para el campo: a) la modalidad retórica exhortativa y su manifestación en el texto a través del Modo verbal y el uso de deícticos y b) las estrategias lingüísticas de ocultamiento de información evidenciadas en el uso del pronombre demostrativo neutro y artículo neutro. La primera característica mencionada, nos remite al hecho de que la modalidad retórica predominante en estos mensajes es la exhortativa y se expresa en diversos elementos lingüísticos: el modo y la modalidad del verbo y deícticos. Como consecuencia de la modalidad exhortativa, se observa el predominio del modo Imperativo y los deícticos de tiempo futuro, de adverbios de lugar (allí- allá) y de deícticos de $2^{\circ}$ persona. 


\section{MODALIDADES RETÓRICAS, TIEMPOS VERBALES Y ESTRATEGIAS LINGUÍSTICAS EN LOS MENSAJES PARA EL CAMPO}

En la construcción textual de los "Mensajes para el Campo" se utilizan diversas modalidades retóricas y estrategias lingüístico-comunicativas que dan cuenta del modo, es decir la tercera dimensión que forma parte de la caracterización del registro textual

a) Modalidad retórica exhortativa, su manifestación en el modo verbal y deícticos

En el análisis del modo verbal, se observa el predominio del Modo Imperativo frente al Modo Indicativo, Subjuntivo e Infinitivo. Sin embargo, la modalidad predominante en la construcción de los "mensajes", no siempre se expresa mediante el modo imperativo del verbo, pues tanto el Modo Subjuntivo como el Modo Infinitivo adquieren la modalidad impresiva, es decir, a través de distintos modos verbales se manifiesta la intención comunicativa del hablante y la función de los textos; esto es ordenar, exhortar, llamar la atención del oyente, dar una orden. Este hecho (asignar una modalidad a distintas formas modales) lo podemos observar en los siguientes ejemplos:

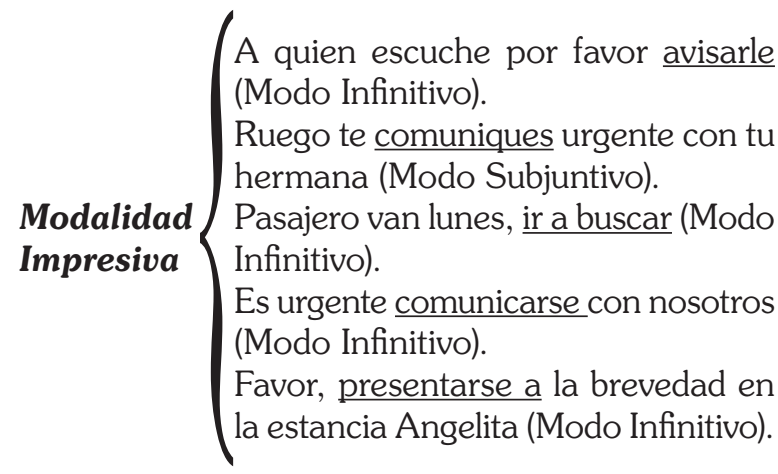

Diversos autores (Alarcos, 1990; Bosque y Demonte, 1999) han observado que este traspaso de modalidades (cuya función es comunicar intenciones) es propio del estilo coloquial, coincidiendo con lo observado en nuestro estudio, se señala que los hablantes para expresar la modalidad impresiva, usan el presente de subjuntivo, y en un estilo coloquial el modo infinitivo.

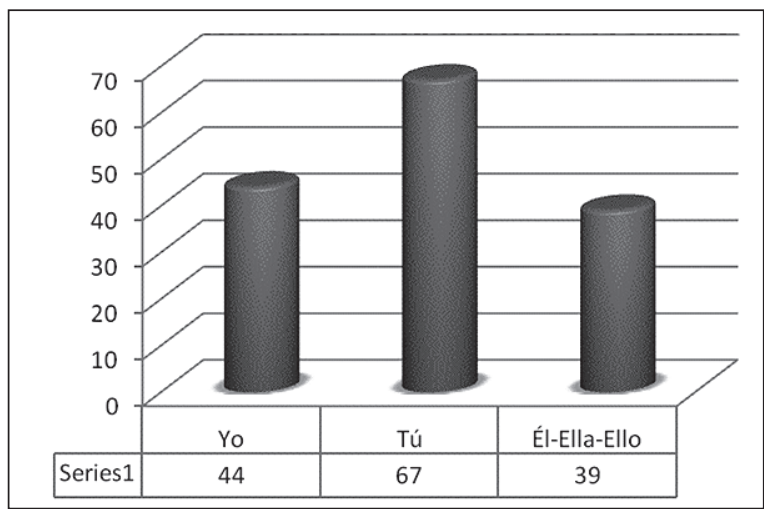

Fig. 1. Deícticos de personas predominantes en los Mensajes para el campo.

Como hemos señalado, la modalidad impresiva se expresa en distintos elementos lingüísticos, entre ellos se destacan el uso de deícticos de $2^{\circ}$ persona, de tiempo futuro, de adverbios de lugar (allí- allá). En los siguientes gráficos se presenta la frecuencia y predominio de los deícticos identificados en el análisis del Modo.

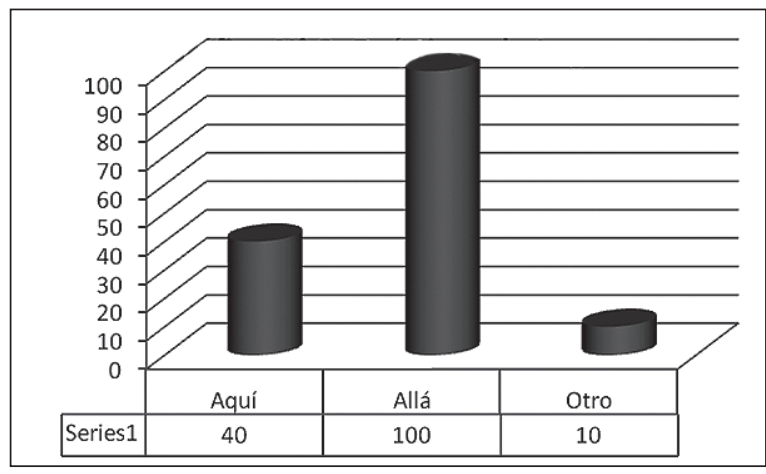

Fig. 2. Deícticos de lugar predominantes en los Mensajes para el campo.

Como podemos observar el deíctico de $2^{\mathrm{a}}$ persona es mayormente usado, en tanto estos mensajes están dirigidos a un Tú o usted, al cual se le solicita realizar determinadas acciones (Modalidad retórica Impresiva). Los ejemplos siguientes grafican esta tendencia: "deje (Usted), en el puesto llave del puente Miraflores"/ "encierra (Tú) unos 8 borregos machos del 2 para mañana al medio día". 


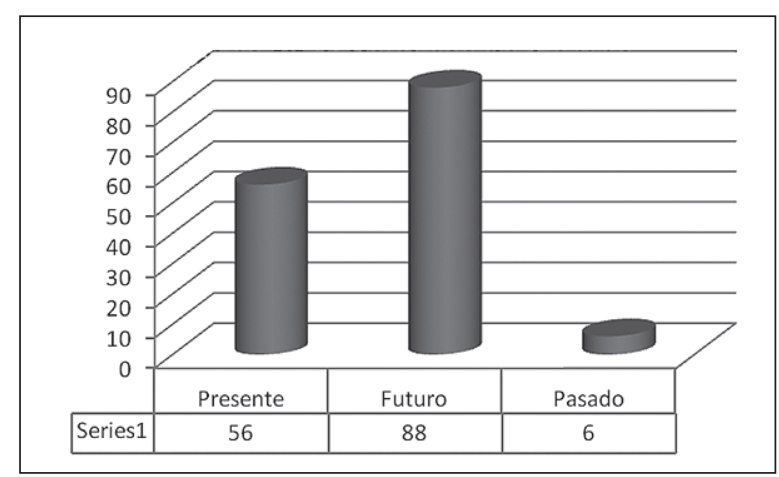

Fig. 3. Deícticos de tiempo predominantes en los "Mensajes para el campo".

Los deícticos de lugar predominantes orientan las acciones hacia un lugar distante, ello se observa en los casos como: "Vaya a esa el sábado", "Mañana en la mañana estoy en esa".

Las instrucciones transmitidas mediante los diversos mensajes orientan a realizar una acción en un futuro cercano: "Encierra unos borregos para mañana al medio día"/ "mañana a primera hora rodear piño de borregos a los corrales".

b) Estrategias lingüísticas de ocultamiento de información evidenciadas en el uso del pronombre demostrativo neutro y artículo neutro.

La identificación de elementos deícticos que evidencian estrategias discursivas de ocultamiento de información, constituyen recursos lingüísticos que aluden a elementos exofóricos del texto, dadas las características de canalización o transmisión del mensaje, estos recursos se destacan en los siguientes mensajes:

1. ...no puedo hacer lo acordado y requiero lo que te pedí

2. Lo que tú sabes probablemente hasta fines de septiembre

3. Ruego depositar lo acordado

4. Vaya a esa el sábado

5. Javier vaya hoy a esa

6. Yo te explico lo demás

7. Mañana en la mañana estoy en esa

8. Espero baje a esa antes del jueves

En estos ejemplos es necesario destacar el uso del pronombre demostrativo "esa", este cumple una función que dista de ser la señalada en las clasificaciones gramaticales del español (Bosque y Demonte, 1999) y se puede interpretar como un rasgo lingüístico dialectal, pero que además tiene una función principalmente de ocultamiento de información, adquiriendo un valor que supera el reconocido gramaticalmente. La gramática define estos pronombres demostrativos como unidades lingüísticas que permiten señalar objetos de la realidad, es decir, tienen función deíctica. Son los encargados de situar en las coordenadas de espacio y tiempo los objetos relacionados con las personas que intervienen en el acto de la comunicación. En ese momento nos tuvimos que ir, ese día ya lo verás; Cuando los demostrativos establecen deixis espacial o temporal, se toma como punto de referencia, subjetivo, la posición del hablante; este indica una distancia pequeña, ese indica una distancia algo mayor y aquel una distancia aún mayor con respecto al hablante.

En los ejemplos extraídos, podemos realizar el siguiente análisis del pronombre demostrativo:

1. Mañana en la mañana estoy en esa(*)

2. Espero baje a esa $\left({ }^{*}\right)$ antes del jueves

- "En ambos casos "esa" deja de cumplir la función de situar en las coordenadas de espacio y tiempo los objetos relacionados con las personas que intervienen en el acto de la comunicación.

Una interpretación de este hecho podemos explicarlo a partir de la transposición del uso de pronombres, en nuestros ejemplos es usado el pronombre demostrativo "ESA", dejando de establecer la deixis espacial, para cumplir la función del demostrativo neutro. Estos pronombres son expresiones referenciales con un valor deíctico locativo, sus referentes no son entidades humanas, no sólo identifican entidades físicas, sino también entidades de $2^{\circ}$ y $3^{\circ}$ orden (acontecimientos o estados de cosas) , pueden indicar además conjunto de objetos ideas o situaciones. Esta variedad de propiedades semánticas contribuye a que la referencia de los demostrativos neutros sea a menudo más indeterminado que la de los pronombres demostrativos de género masculino y femenino y los convierte en formas polivalentes, particularmente aptas para el uso simbólico, textual y exofórico, su comportamiento se asemeja al del artículo neutro en algunos de sus usos, compartiendo dos valores de "LO" (individuativo con denotación absoluta y el "lo" factivo). El artículo neutro y el 
demostrativo identifican una entidad individual o compleja no humana, ambas expresiones (eso y lo) son expresiones referenciales que establecen una relación de carácter impreciso o abstracto con su referente.

\section{CONCLUSIONES}

El análisis de las categorías campo-tenor y modo en Los Mensajes para el campo, explica la configuración del mensaje, que expresa el carácter especial del "contexto de situación", entre las conclusiones principales, y a partir del análisis de las categorías establecidas (Campo-Tenor-Modo) se observa en los textos el predominio de dos temáticas (Campo): laboral y familiar; a su vez las relaciones de roles entre los participantes (Tenor) son predominantemente asimétricas. La modalidad retórica predominante en estos mensajes (Modo) es la exhortativa, como consecuencia de ello, se observa el predominio de deícticos de $2^{\circ}$ persona, de tiempo futuro y de adverbios de lugar (allí- allá). Estas opciones lingüísticas se explican a partir de que el lenguaje se estructura y organiza en función de satisfacer exigencias comunicativas propias de un medio de comunicación que conecta el mundo rural con el urbano con la finalidad de resolver situaciones cotidianas. Por otro lado, estos textos plantean la necesidad de que el carácter privado de este mensaje no sea descifrado por la audiencia radial propia de un canal público, por ello el uso de estrategias discursivas de ocultamiento de información, tales como el demostrativo neutro ("esa") y el artículo neutro "lo", partículas de la lengua que satisfacen esta demanda de privacidad en un medio de comunicación masiva.

La distinción teórica inicial planteada respecto de la relación entre texto y discurso, en el caso de los Mensajes para el campo es particularmente notoria, pues en definitiva los textos están determinados por la situación discursiva, haciendo indisoluble la relación entre texto y discurso, en este tipo de mensajes, se comprueba que la construcción lingüística de un texto se elabora considerando el contexto de situación en la cual se encuentra inmerso. Al mismo tiempo, los participantes despliegan diversas estrategias que le permiten hacer funcionar el lenguaje, en una situación de comunicación masiva, comunicando y a la vez ocultando información de carácter privado.
Al mismo tiempo podemos concluir que los "mensajes para el campo" constituyen una variedad textual dialectal, que refleja la adecuación del texto al contexto y a su vez expresa la diversidad de los procesos sociales (Halliday, 1989). De este modo, observamos que el registro específico de los textos analizados, se expresa en variables que concurren situacionalmente y se materializan en las características lingüísticas destacadas en nuestro análisis. Es decir el registro, entendido como variedad de lengua caracterizada por su gramática y su léxico, se manifiesta en los "Mensajes para el campo" como un macro nivel retórico-gramatical donde se realizan las manifestaciones del discurso y las variedades lingüísticas.

Finalmente, dadas sus características textuales, este tipo de mensajes permite reconocer elementos propios de la cultura que rodea el mundo rural patagónico y comprobar la permanencia de actividades, relaciones, labores que desde el mundo urbano pueden ser transmitidos a través de la emisión radial.

\section{BIBLIOGRAFÍA}

ALARCOS, E. 1990. Estudios de gramática funcional del español. Madrid: Gredos.

ALMEIDA, M. 2003. Sociolingüística. España: Universidad La Laguna.

ALVAREZ, G. 2004. Textos y Discursos. Introducción a la lingüística del texto. Chile: Universidad de Concepción.

BEAUGRANDE, R. Y DRESSLER, W. 1997. Introducción a la lingüística del texto. Barcelona: Ariel.

BOSQUE, I. Y DEMONTE, V. 1999. Gramática descriptiva del español. Madrid: Espasa Calpe.

CALSAMIGLIA, H. Y TUSÓN, A. 2007. Las cosas del decir: Manual de análisis del discurso. Barcelona: Ariel.

CORVALÁN, C. 1989. Sociolingüística. Teoría y análisis, España: Alhambra.

DUCROT, O. 1980. El decir y lo dicho. Barcelona: Ariel.

EGGINS, S. Y MARTIN, J. 2003. El contexto como género: una perspectiva lingüística funcional, Signos, XXXVI, 54, 185-205

HALLIDAY, M. 1975. Estructura y función del lenguaje. En J. Lyons (Comp.), Nuevos Horizontes de la lingüística (pp. 145-173). Madrid: Alianza.

HALLIDAY, M. 1989. Functions of language. En M. Halliday y R. Hasan (Eds.), Language, context, and text: Aspects of language in a social-semiotic perspective (pp. 15-28). Oxford: Oxford University Press. 
HALLIDAY, M. 1994a. El Lenguaje como semiótica social. La interpretación social del lenguaje y el significado. México: Fondo de Cultura Económica.

HALLIDAY, M. 1994b. An Introduction To Functional Grammar. Londres: Arnold.

HALLIDAY, M Y HASAN, R. 1976. Cohesion in English. London: Longman.

HERNÁNDEZ, CÉSAR. 1999. Gramática funcional del español. Madrid: Gredos.

KINTSCH, W. Y VAN DIJK, T.A. 1978. Toward a model of text comprehension and production. Psychological Review, 85 (5), 363-394.

LABOV, W. 1983. Los modelos sociolingüísticos. Madrid: Cátedra.
MARTINIC, M. 1972. Magallanes. Síntesis de Tierra y Gentes. Buenos Aires: Francisco de Aguirre.

MARTINIC, M. 2006. Historia de la región magallánica. Punta Arenas: Universidad de Magallanes.

MARTINIC, M. Y BURATOVIC. 2007. Las comunicaciones a distancia en Magallanes. Chile: Ediciones La Prensa Austral.

RENKEMA, J. 1999. Introducción a los estudios sobre el discurso. Barcelona: GEDISA.

SILVA, C. 1989. Sociolingüística. Teoría y análisis, España: Alambra.

VAN DIJK, T. 1998. Estructuras y funciones del discurso. Madrid: Alianza. 